\title{
Influência do suporte e fixação anterior na resistência mecânica do fixador interno vertebral
}

\author{
The influence of anterior reconstruction and fixation on the mechanical \\ performance of an internal fixator
}

\author{
Influencia del soporte y de la fijación anterior sobre la resistencia \\ mecánica del fijador interno vertebralartrodesis cervical anterior por \\ hernia del disco cervica
}

\author{
Gisele Cristina Ale dos Santos ${ }^{1}$ \\ Antonio Carlos Shimano² \\ Helton LA Defino ${ }^{3}$
}

\section{RESUMO}

Objetivo: avaliar a influência da reconstrução e fixação anterior no desempenho mecânico do fixador interno da coluna vertebral. Métodos: foram formados três grupos experimentais de acordo com a reconstrução e fixação anterior: grupo I -sem suporte anterior; grupo II - com suporte anterior; grupo III - com suporte e fixação anterior. Os corpos de prova foram submetidos a ensaios mecânicos de flexo-compressão, flexão lateral e torção, realizados em máquina de universal de ensaios, tendo sido realizados dez ensaios para cada modalidade (flexo-compressão, flexão lateral e torção) em cada grupo experimental, perfazendo um total de 90 ensaios mecânicos. As propriedades mecânicas estudadas foram: o momento-fletor, o torque e a rigidez obti-

\begin{abstract}
Objective: evaluation of the mechanical stability of the internal vertebral fixation through the influence of the anterior load bearing reconstruction and stabilization. Methods: cylindrical woods blocks were utilized as test bodies and were stabilized by an internal fixation. Three experimental groups were set according to the anterior reconstruction and fixation: group I - without anterior support; group II - with anterior support and group III - with support and anterior fixation. In an universal assay machine the wood block underwent to flexioncompression, lateral flexion and torsion mechanical assays, until ten assays of eachmodalitywereperformed (flexioncompression, lateral compression and torsion) in each experimental group,
\end{abstract}

\section{RESUMEN}

Objetivo: evaluar la influencia de la reconstrucción y fijación anterior en el desempeño mecánico del fijador interno de la columna vertebral. Métodos: fueron formados tres grupos experimentales de acuerdo com la reconstrucción y fijación anterior: grupo I- sin soporte anterior, grupo II- con soporte anterior y grupo III- con soporte y fijación anterior. Los cuerpos de prueba fueron sometidos a ensayos mecánicos de flexocompresión, flexión lateral y torción, realizados en la máquina universal de ensayos, habiéndose realizados 10 ensayos para cada modalidad (flexocompresión, flexión lateral y torción) en cada grupo experimental,con untotal de 90 ensayos mecánicos. Las propiedades mecánicas estudiadas

\footnotetext{
Trabalho realizado no Laboratório de Bioengenharia do Departamento de Biomecânica, Medicina e Reabilitação do Aparelho Locomotor da Faculdade de Medicina de Ribeirão Preto da Universidade de São Paulo - USP - Ribeirão Preto (SP), Brasil.

'Pós-graduanda do Departamento de Biomecânica, Medicina e Reabilitação do Aparelho Locomotor da Faculdade de Medicina de Ribeirão Preto da Universidade de São Paulo - USP - Ribeirão Preto (SP), Brasil.

2Doutor, Professor do Departamento de Biomecânica, Medicina e Reabilitação do Aparelho Locomotor da Faculdade de Medicina de Ribeirão Preto da Universidade de São Paulo - USP - Ribeirão Preto (SP), Brasil.

3Professor Titular do Departamento de Biomecânica, Medicina e Reabilitação do Aparelho Locomotor da Faculdade de Medicina de Ribeirão Preto da Universidade
} de São Paulo - USP - Ribeirão Preto (SP), Brasil. 
dos a partir da curva carga x deflexão de cada ensaio mecânico. Resultados: observou-se que a colocação do suporte e da fixação anterior aumentou a resistência mecânica nos ensaios de flexo-compressão. Nos ensaios de flexão lateral observou-se aumento da resistência mecânica somente com a fixação anterior. Conclusão: nos ensaios de torção o suporte anterior e a fixação anterior não aumentaram a resistência mecânica do sistema de fixação vertebral.

DESCRITORES: Dispositivos de fixação ortopédica; Fixadores internos; Biomecânica; Coluna vertebral in a total of 90 mechanical assays. The studied mechanical proprieties were the flex moment, torsion moment and the stiffness, obtained through the load $x$ deflection of each mechanical trial. Results: it was observed that utilizing a support and anterior fixation there has been na increased mechanical stiffness in the flexion-compression mechanical assays. In the lateral flexion tests it was observedanincreasedrigidityonlywith the anterior fixation. Conclusion: with the torsion tests the anterior support and fixation did not increase the mechanical rigidity of the vertebral fixation system.

KEYWORDS: Orthopedic fixation devices; Internal fixators; Biomechanics; Spine fueron el momento-flexor, la torción y la rigidez obtenidas a partir de la curva carga $x$ deflexión de cada ensayo mecánico. Resultados: fue observado que la colocación del soporte y de la fijación anterior aumentaron la resistencia mecánica en los ensayos de flexo-compresión. En los ensayos de flexión lateral fue observado aumento de la resistencia mecánica solamente con la fijación anterior. Conclusión: en los ensayos de torción, el soporte anterior y la fijación anterior no aumentaron la resistencia mecánica del sistema de fijación vertebral.

DESCRIPTORES: Dispositivos de fijación ortopédica; Fijadores internos; Biomecánica; Columna

\section{INTRODUÇÃO}

Os conceitos e fundamentos biomecânicos têm orientado a utilização dos implantes na coluna vertebral e acompanhado o desenvolvimento das técnicas de fixação e tratamento cirúrgico das doenças da coluna vertebral.

Os estudos biomecânicos têm demonstrado que na posição ereta a porção anterior da coluna vertebral (corpo e disco intervertebral) absorve 80 a $90 \%$ da força de compressão axial, enquanto que os 10 a $20 \%$ restantes são suportados pelas articulações posteriores ${ }^{1-3}$. A restauração da porção anterior da coluna vertebral e a manutenção da sua integridade permitem que os implantes aplicados sobre a face posterior da coluna vertebral atuem como tirante de tensão, evitando a sua quebra ou arrancamento do osso provocados pelos momentos de força produzidos na ausência da integridade da coluna anterior ${ }^{4-6}$.

A evolução técnica dos implantes vertebrais permitiu a associação da reconstrução e fixação anterior do segmento vertebral $^{1,3-4}$, tendo sido esse o alvo do estudo realizado.

O objetivo do estudo foi avaliar a influência da reconstrução e fixação anterior no desempenho mecânico do fixador interno da coluna vertebral.

\section{MÉTODOS}

Foram utilizados corpos de prova de madeira com diâmetro de $55 \mathrm{~cm}$ e comprimento de $95 \mathrm{~mm}$, simulando as vértebras do segmento vertebral, sobre o qual o sistema de fixação vertebral foi aplicado.

Foi confeccionado um guia para a perfuração dos orifícios nos corpos de prova. O guia era constituído de um cilindro de madeira com $55 \mathrm{~mm}$ de diâmetro e $46 \mathrm{~mm}$ de comprimento, sobre o qual era aplicada uma placa metálica contendo os orifícios para as perfurações. Os orifícios formavam um ângulo de $30^{\circ}$ entre si e estavam afastados $40 \mathrm{~mm}$ no sentido transversal e $76 \mathrm{~mm}$ no sentido longitudi- nal (Figura 1). O guia era posicionado entre os corpos de prova para a realização das perfurações, com o objetivo de padronizar a realização das perfurações nos corpos de prova. A perfuração foi realizada por meio de brocas e quatro pinos de Shanz de $5 \mathrm{~mm}$ de diâmetro inseridos nos orifícios. Os pinos de Shanz eram introduzidos a uma profundidade de $3,5 \mathrm{~mm}$ e acoplado às conexões do sistema do fixador interno (Synthes) juntamente com as hastes longitudinais, que eram posicionas a $10 \mathrm{~mm}$ dos corpos de prova (Figura 2).
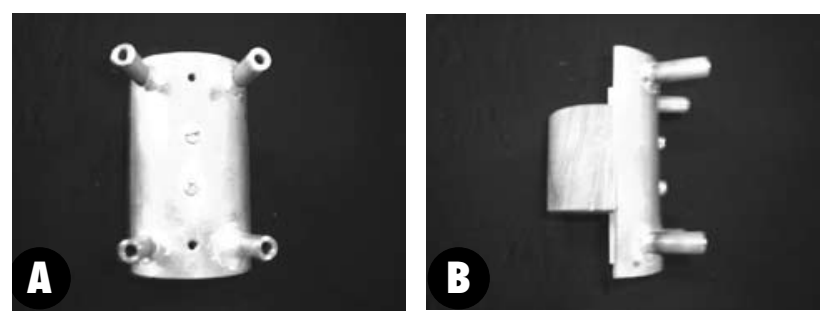

Figura 1

Vista anterior (A) e lateral (B) do guia utilizado para a perfuração dos corpos de prova

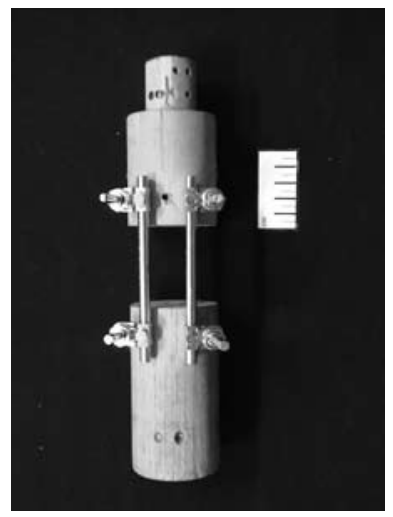

Figura 2

Fotografia do corpo de prova estabilizado com o fixador interno 
Com o objetivo de avaliar a influência da reconstrução e fixação anterior foram formados três grupos experimentais:

I - ausência da interposição de suporte anterior;

II - colocação de suporte anterior (interposição de bloco de madeira de $46 \mathrm{~mm}$ de comprimento e $22 \mathrm{~mm}$ de diâmetro na região central entre os corpos de prova);

III - colocação do suporte anterior (interposição do bloco de madeira de $22 \mathrm{~mm}$ de diâmetro e $46 \mathrm{~mm}$ de comprimento na região central entre os corpos de prova), associado com a fixação anterior dos corpos de prova e do bloco de madeira interposto por meio de três parafusos de $5 \mathrm{~mm}$ de diâmetro externo e $40 \mathrm{~mm}$ de comprimento acoplados a uma barra longitudinal de $6 \mathrm{~mm}$ de diâmetro (Sistema USS - Synthes). Todos os implantes utilizados no estudo eram de aço inoxidável (Figura 3).

Os corpos de prova foram submetidos a ensaios mecânicos em máquina universal de ensaios (MUE), realizados na fase elástica do material com o controle e a medida das cargas e deformações efetuadas pelo programa de computador TESC versão 1.10.

Foram realizados ensaios mecânicos de flexo-compressão, flexão lateral e torção em cada grupo experimental. Nos ensaios de flexo-compressão a pré-carga era de $15 \mathrm{~N}$ velocidade de aplicação da carga de $1 \mathrm{~mm} / \mathrm{min}$, a deformação linear máxima de $1,5 \mathrm{~mm}$. O ponto de aplicação da carga estava localizado na face superior do corpo de
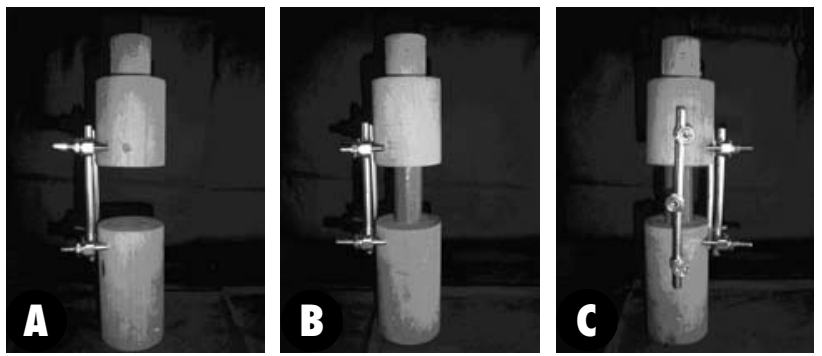

Figura 3

Fotografia em perfil dos corpos de provas dos três grupos experimentais. I - sem suporte anterior (A), II - com suporte anterior (B) e III - com suporte e fixação anterior (C)

\section{RESULTADOS}

Os resultados dos ensaios de flexo-compressão estão representados nas tabelas 1 e 2 e figuras 5 e 6 . Foi observado que a média do momento fletor foi de 7,37 $\pm 0,68 \mathrm{~N}$.m, no grupo I (sem suporte anterior); de 52,31 $15,2 \mathrm{~N} . \mathrm{m}$, no grupo II (suporte anterior); e de $63,39 \pm 8,68 \mathrm{~N} . \mathrm{m}$, no grupo III (suporte anterior e fixação). Foi observada diferença estatística significativa entre os valores do grupo I e II $(p<0,001)$ e entre os grupos II e III $(\mathrm{p}<0,001)$.

A média dos valores da rigidez nos testes de flexocompressão foi de: $112,57 \pm 12,09103 \mathrm{~N}$.m no grupo I; $1911,33 \pm 608,3710-3 \mathrm{~N} / \mathrm{m}$ no grupo II; e $2135,04 \pm 151,50$ 10-3 N/m no grupo III. Foi observada diferença estatística significativa entre os valores da rigidez do grupo I e II $(p<0,001)$ e entre os valores do grupo II e III $(p<0,001)$. prova e a 40mm da base do implante, paralelo e oposto ao sistema de fixação. Nos ensaios de flexão-lateral foi utilizada pré-carga de $5 \mathrm{~N}$, velocidade de aplicação de carga de $1 \mathrm{~mm} / \mathrm{min}$, deformação linear máxima de $2,0 \mathrm{~mm}$. As cargas eram aplicadas a uma distância de $180 \mathrm{~mm}$ do ponto de fixação do corpo de prova (Figura 4). Nos ensaios de torção a pré-carga era de $20 \mathrm{~N}$, a velocidade da aplicação de carga de $1 \mathrm{~mm} / \mathrm{min}$,o limite de deformação angular de $9,5^{\circ}$. A célula de carga utilizada em todos os ensaios foi de $200 \mathrm{Kg}$.

Foram realizados dez ensaios mecânicos para cada modalidade de aplicação da força (flexo-compressão, flexão lateral e torção) em cada grupo experimental, perfazendo um total de 90 ensaios mecânicos.

Cada ensaio mecânico resultava numa curva de carga $\mathrm{x}$ deflexão, a partir da qual foram estudadas e comparadas as propriedades mecânicas: momento fletor, torque e rigidez.

A comparação entre os valores dos diferentes grupos experimentais foi realizada por meio de estudo estatístico, tendo sido utilizada a Análise de Variância (ANOVA) para a comparação simultânea entre as variáveis flexão lateral (rigidez e momento fletor), flexo compressão (rigidez e momento fletor) e torção (rigidez e momento torsional). Nas comparações post hoc foi utilizado o método de Bonferroni, tendo sido adotado o nível de significância $\mathrm{p} \leq 0.05$.
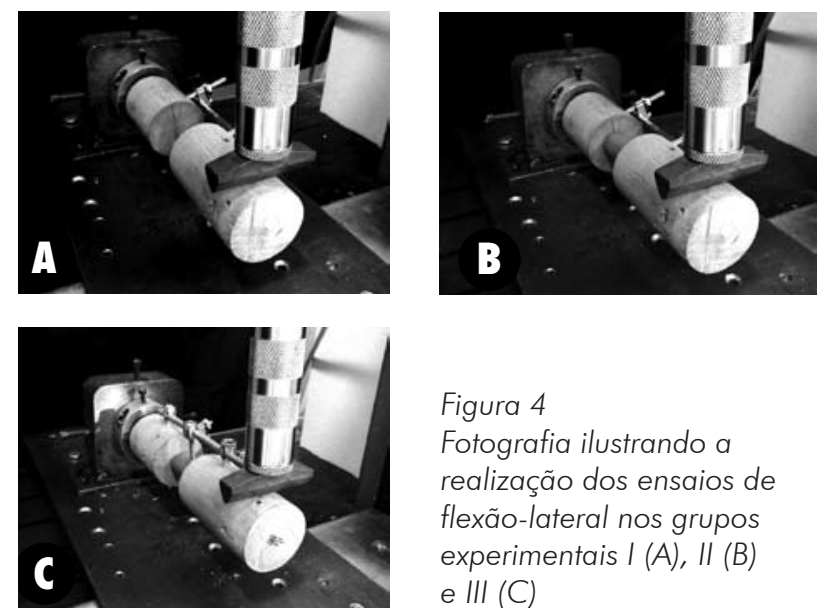

Figura 4

Fotografia ilustrando a realização dos ensaios de flexão-lateral nos grupos experimentais I (A), II (B) e III (C)

\section{Momento fletor (flexo-compressāo)}

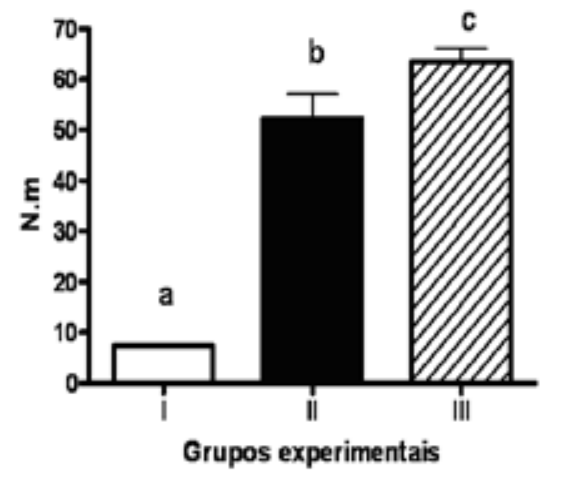

Figura 5

Gráfico

ilustrando os resultados do momento fletor. As letras ( $a, b$ e c) indicam a diferença estatística entre os três grupos experimentais 


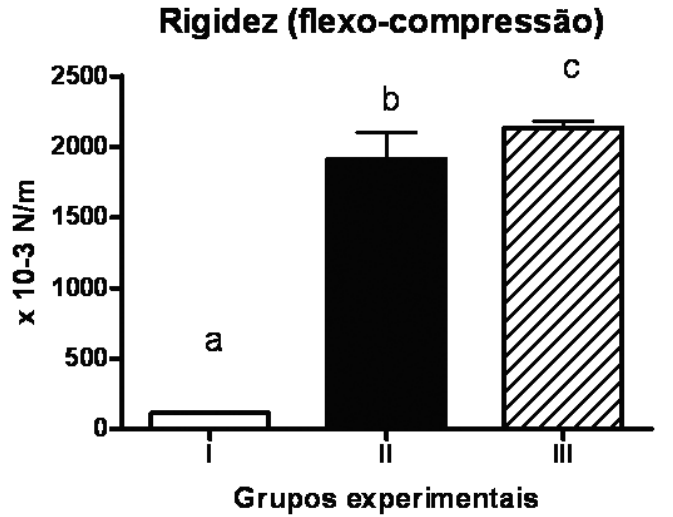

Figura 6

Gráfico ilustrando os resultados da rigidez observados nos ensaios de flexo-compressão. As letras ( $a, b$ e c) indicam a diferença estatística entre os grupos experimentais

Os resultados dos ensaios mecânicos de flexão-lateral estão representados nas tabelas 1 e 2 e figuras 7 e 8 . A média dos valores do momento fletor foi de 5,20 \pm 0.96 N.m no grupo I; $6,32 \pm 1,06$ N.m no grupo II; e 11,18 $\pm 1,73$ N.m no grupo III. Não foi observada diferença estatística significativa entre os valores do momento fletor nos ensaios de flexão lateral entre os grupos I e II $(p>0,05)$. Foi observada diferença estatística significativa entre os valores do grupo I e II com relação ao grupo III $(\mathrm{p}<0,001)$.

A média dos valores da rigidez nos ensaios de flexão lateral foi de $10,74 \pm 2,78 \mathrm{~N} / \mathrm{m}$ no grupo I; $13,95 \pm 3,13 \mathrm{~N}$.m no grupo II e $25,88 \pm 4,87$ N.m no grupo III. Não foi observada diferença estatística significativa entre os valores dos grupos experimentais I e II ( $p>0,05)$. Foi observada diferença estatística significativa entre os valores dos grupos I e II com relação aos valores do grupo III ( $\mathrm{p}<0,001)$.
Rigidez (flexão lateral)

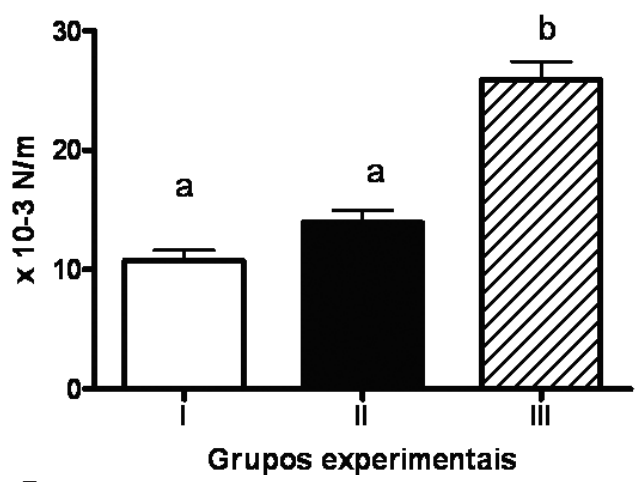

Figura 7

Gráfico ilustrando os resultados do momento fletor nos ensaios de compressão lateral. As letras (a e b) indicam a diferença estatística entre os grupos experimentais

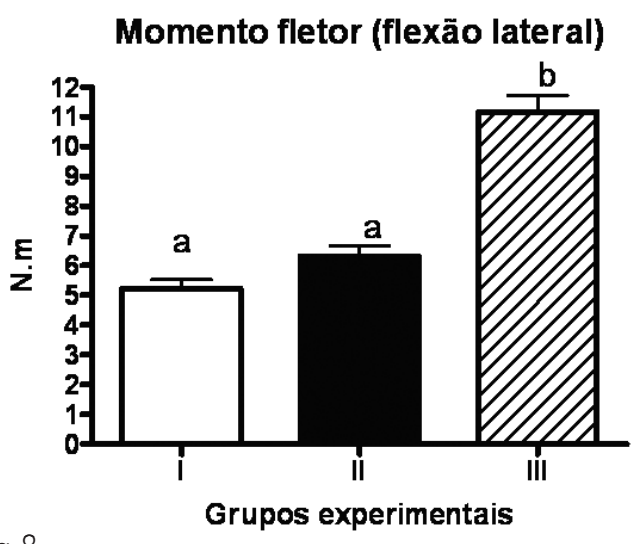

Figura 8

Gráfico ilustrando os valores da rigidez observados nos ensaios em flexão lateral. As letras (a e b) indicam a diferença estatística entre os grupos experimentais)

TABELA 1 - Valores da média do momento fletor (N.m) nos ensaios de flexo-compressão e flexão lateral e torque nos ensaios de torção

\begin{tabular}{llll}
\hline \multicolumn{4}{c}{ Grupos } \\
\hline I & \multicolumn{1}{c}{ II } & III \\
\hline Flexo-compressão & $7,37 \pm 0,68\left(^{*}\right)$ & $52,31 \pm 15,2\left(^{* *}\right)$ & $63,39 \pm 8,68\left(^{* * *}\right)$ \\
Flexão lateral & $5,22 \pm 0,96\left(^{*}\right)$ & $6,32 \pm 1,06\left(^{*}\right)$ & $11,18 \pm 1,73\left(^{* *}\right)$ \\
Torção & $0,94 \pm 0,23$ & $1,09 \pm 0,18$ & $1,3 \pm 0,20$
\end{tabular}

Os astericos $\left({ }^{*}\right)$ indicam a diferença estatística significativa entre os grupos experimentais

TABELA 2 - Valores da média da rigidez (x 10-3 N/m) nos ensaios de flexo-compressão, flexão lateral e torção

\begin{tabular}{lccc}
\hline \multicolumn{4}{c}{ Grupos } \\
\hline Flexo-compressão & $112,57 \pm 2,09\left(^{*}\right)$ & $1911,33 \pm 608,37\left(^{* *}\right)$ & $2135,04 \pm 151,50\left(^{* * *}\right)$ \\
Flexão lateral & $10,74 \pm 2,78\left(^{*}\right)$ & $13,95 \pm 3,13\left(^{*}\right)$ & $25,88 \pm 4,87\left(^{* *}\right)$ \\
Torção & $0,072 \pm 0,026$ & $0,0914 \pm 0,024$ & $0,093 \pm 0,24$ \\
\hline
\end{tabular}

Os astericos $\left(^{*}\right)$ indicam a diferença estatística significativa entre os grupos experimentais 
A estabilidade do sistema nos ensaios de flexão lateral não foi aumentada com a colocação do suporte anterior. No entanto, a fixação lateral adicional aumentou a resistência da montagem nos ensaios de flexão lateral.

Os resultados dos ensaios de torção estão representados na tabelas 1 e 2 e figuras 9 e 10 . A média dos valores do momento torcional foi de $0,94 \pm 0,23$ N.m no grupo I; $1,09 \pm 0,18$ N.m no grupo II; e 1,3 $\pm 0,20$ N.m no grupo III. Não foi observada diferença estatística entre os valores dos três grupos experimentais $(\mathrm{p}=0,13)$.

Os valores da rigidez observados nos ensaios de torção foram de $0,072 \pm 0,026 \mathrm{~N} . \mathrm{m}$ no grupo I; $0,0914 \pm 0,024 \mathrm{~N} / \mathrm{m}$ no grupo II ; e $0,093 \pm 0,024 \mathrm{~N} / \mathrm{m}$ no grupo III, não tendo sido observado diferença estatística significativa.

Os resultados dos ensaios mecânicos mostraram que a utilização do suporte anterior aumentou a resistência mecânica da montagem nos ensaios de flexo-compressão, e que a fixação anterior lateral adicional acrescentou mais estabilidade ao segmento fixado. Nos ensaios de flexão lateral a utilização do suporte anterior não alterou as propriedades mecânicas da fixação, e a fixação anterior lateral adicional acrescentou mais estabilidade ao segmento fixado.

Nos ensaios mecânicos de torção a utilização do suporte anterior ou da fixação anterior lateral adicional não influenciaram nas propriedades mecânicas do segmento fixado.

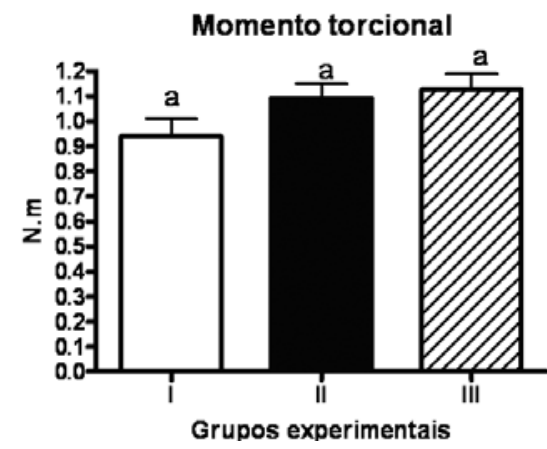

Figura 9

Gráfico ilustrando os valores do momento torcional observado nos ensaios de torção nos três grupos experimentais. As letras (a) indicam que não foi observada diferença estatística entre os grupos experimentais

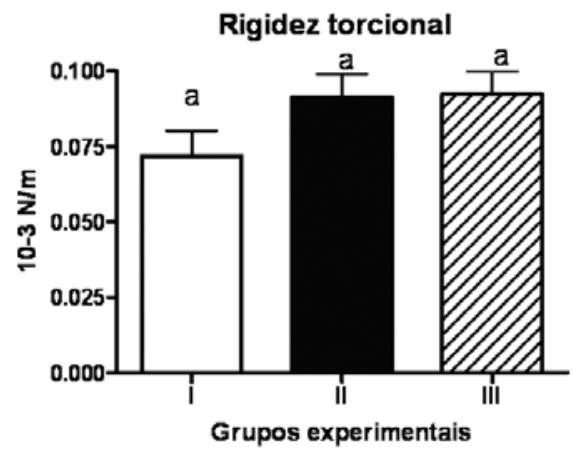

Figura 10

Gráfico ilustrando os valores da rigidez nos ensaios de torção. As letras (a) indicam que não foi observada diferença estatística entre os grupos experimentais

\section{DISCUSSÃO}

Os conceitos biomecânicos da coluna vertebral tem orientado o desenvolvimento e a aplicação dos implantes vertebrais, e a importância da parte anterior do segmento vertebral no suporte e transmissão da carga tem se destacado na evolução dos conceitos relacionados coma cirurgia da coluna vertebral $1^{1,3-4,7}$.

Os ensaios mecânicos realizados tiveram como objetivo principal a observação das propriedades mecânicas do sistema de fixação vertebral, considerando-se não somente a reconstrução da coluna anterior, mas também a estabilização anterior por meio de implantes, considerando-se ainda os diferentes planos da aplicação das forças nos ensaios mecânicos.

Os ensaios mecânicos e as diferentes modalidades de fixação tiveram como principal objetivo a simulação das diferentes opções de reconstrução da coluna anterior e a sua resposta à aplicação das forças nos diferentes planos.

O modelo experimental utilizado em nosso estudo foi baseado na utilização de blocos de madeira, que tem sido empregado em estudos semelhantes ${ }^{7-8}$, e permite eliminar algumas variáveis como a densidade óssea, a angulação dos pedículos vertebrais, tornando o material mais homogêneo e facilitando as comparações entre os diferentes tipos de montagens. No entanto, não deve deixar de ser mencionada a dificuldade da reprodução da situação real representada pelo segmento vertebral contendo os ligamentos, músculos e outros elementos de sustentação.

A importância da reconstrução anterior pode ser corroborada nos testes de flexo-compressão e flexão lateral. Os resultados dos ensaios mecânicos mostraram que as duas variáveis estudadas (o suporte anterior e a fixação anterior) influenciaram as propriedades mecânicas do sistema de fixação, e com exceção dos ensaios mecânicos de torção a utilização do suporte anterior ou da fixação anterior não alteraram as propriedades mecânicas do sistema de fixação.

A extrapolação dos resultados de ensaios mecânicos devem ser extrapolados com muita cautela para as situações clínicas. No entanto, corroborando as observações clínicas $^{2-4}$ a reconstrução da coluna anterior aumentou a resistência mecânica do fixador interno nos testes de flexo-compressão, indicando que a reconstrução da coluna anterior permite a aplicação de maior carga axial.

A reconstrução da coluna anterior isolada não influenciou o desempenho do fixador interno nos ensaios de flexão lateral e torção, sendo que a fixação anterior por meio de implantes foi o parâmetro de auxiliou no desempenho mecânico da fixação.

Os implantes e sistemas de fixação vertebral têm sido utilizados com diferentes objetivos no âmbito da cirurgia da coluna vertebral, e o desempenho mecânico desses sistemas pode ser alterado e melhorado por meio da reconstrução e fixação anterior do segmento vertebral afetado. 


\section{CONCLUSÃO}

A utilização do suporte anterior aumentou a resistência mecânica do sistema de fixação somente nos ensaios de flexo-compressão, não apresentando influencia nos ensaios de flexão lateral e torção.

A utilização do suporte e fixação anterior adicional aumentou a resistência mecânica do sistema de fixação vertebral nos ensaios de flexo-compressão e flexão lateral, não apresentando influencia nos ensaios de torção.

O suporte anterior e a fixação anterior adicional não influenciaram a resistência da montagem nos ensaios de torção.

\section{REFERÊNCIAS}

1. Dick JC, Brodke DS, Zdeblick TA, Bartel BD, Kunz DN, Rapoff AJ. Anterior instrumentation of the thoracolumbar spine. A biomechanical comparison. Spine. 1997;22(7):74450.

2. Lindsey RW, Dick W. The fixateur interne in the reduction and stabilization of thoracolumbar spine fractures in patients with neurologic deficit. Spine. 1991;16(3 Suppl):S140-5.

3. Stoltze D, Harms J. [Correction of posttraumatic deformities. Principles and methods]. Orthopade. 1999;28(8):731-45. Review. German.

4. Aebi M, Etter C, Kehl T, Thalgott J. Stabilization of the lower thoracic and lumbar spine with the internal spinal skeletal fixation system. Indications, techniques, and first results of treatment. Spine. 1987;12(6):544-51.
5. Ashman RB, Galpin RD,

Corin JD, Johnston CE 2nd. Biomechanical analysis of pedicle screw instrumentation systems in a corpectomy model. Spine. 1989;14(12):1398-405.

6. Defino HL, Shimano, AC. Ensaios mecânicos com espaçadores vertebrais. Rev Bras Ortop. 2000; 35(7):235-9.

7. Defino HL, Shimano AC. Ensaios mecânicos de um sistema de fixação pedicular com barra transversal. Acta Ortop Bras. 2001; 9(4):14-20.

8. Góes AL, Shimano AC, Defino HL. Estudo biomecânico da participação do estabilizador transversal na estabilidade mecânica das fixações vertebrais com o fixador interno. Coluna/Columna. 2004; 3(3):122-7.

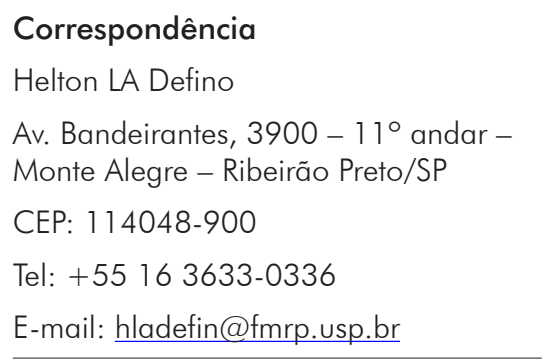

